\title{
WHY DEPRESCRIBING INSTEAD OF NOT PRESCRIBING?
}

\section{Por que desprescrever em vez de não prescrever?}

Welma Wildes Amorimª,b $₫$, Luiz Carlos Passos ${ }^{\mathrm{b}}$, Marcio Galvão Oliveirac $®$

Prescribing medications involves complex cognitive processes, and mistakes in prescription can cause serious adverse events. Deprescribing is one of the last opportunities to prevent patient harm from the use of drugs that should be avoided, especially among older patients. This viewpoint article aims to discuss the prescription process and some essential concepts, such as polypharmacy, prescription of potentially inappropriate medications, and, particularly, the relevance of deprescribing and its relationship with the appropriate prescription of medications in older people.

KEYWORDS: deprescriptions; pharmaceutical preparations; polypharmacy.

A prescrição de medicamentos envolve processos cognitivos complexos e erros na prescrição podem causar eventos adversos

○ graves. A desprescrição é uma das últimas oportunidades de prevenir danos ao paciente decorrentes do uso de medicamentos $\sum$ que devem ser evitados, principalmente entre pacientes mais velhos. Este artigo teve como objetivo discutir o processo de ज prescrição e alguns conceitos essenciais, como a polifarmácia, a prescrição de medicamentos potencialmente inadequados e, Ш particularmente, a relevância da desprescrição e sua relação com a prescrição adequada de medicamentos em idosos.

PALAVRAS-CHAVE: desprescrições; preparações farmacêuticas; polimedicação.

a Department of Natural Sciences, Medicine Course, Universidade Estadual do Sudoeste da Bahia - Vitória da Conquista (BA), Brazil. 'Department of Internal Medicine, Postgraduate Program in Medicine and Health, Universidade Federal da Bahia - Salvador (BA), Brazil. ‘Master's Program in Collective Health, Multidisciplinary Institute in Health, Universidade Federal da Bahia - Vitória da Conquista (BA), Brazil.

Correspondence data

Welma Wildes Amorim - Colegiado de Medicina, Universidade Estadual do Sudoeste da Bahia - Estrada Bem Querer, Km 04, 3293, s/n - Candeias CEP: 45083-900 - Vitória da Conquista (BA), Brazil. E-mail: welmawildes@hotmail.com

Received on: 05/16/2020. Accepted on: 07/18/2020

https://doi.org/10.5327/Z2447-212320202000058 
Ideally, prescribing involves a decision-making process that begins with an accurate diagnosis, followed by an assessment of the balance between the benefits and harms of a particular form of treatment in a patient, and, finally, an assessment of the patient's individual cultural, social, and economic preferences. It also involves the assessment of practical matters related to the choice of drug (e.g., possible interactions with other drugs and disease). Then, the patient and their physician share the decision-making process, a process in which the prescriber and the patient discuss the proposed treatment and its potential effects, both beneficial and adverse, and the need for careful monitoring and dosage adjustment. A break in this process can result in inappropriate prescribing. ${ }^{1}$

Although all providers strive toward rational prescribing, the real goal is to ensure appropriate prescribing. Rational prescribing is the process whereby prescribers logically analyze information available to them before making decisions. Although the use of a logical reasoning process is more likely to result in an appropriate prescribing, a rational argument can still result in an inappropriate prescribing when prescribers are not in possession of all important information or if they fail to consider an important condition. ${ }^{2,3}$

In health care, appropriateness can be defined as "the outcome of a process of decision-making that maximizes net individual health gains within society's available resources."3 This definition implies that appropriate prescribing may be influenced by factors that transcend the logic of the medical perspective, such as the prescriber's feelings, values and intuition, and prior outcomes. ${ }^{2}$ Therefore, appropriate prescribing is a science as well as an art, and the patient's feelings and beliefs are as important in deciding appropriateness as the reasoning that underpins it is. ${ }^{3}$

Potentially inappropriate medication (PIM) refers to the prescription of medications that may increase a patient's risk of adverse health outcomes, given the availability of safer, more effective treatment options, or simply a situation in which the risks of therapy outweigh the benefits. ${ }^{4}$ Inappropriate prescribing takes several forms, and some forms, such as overprescribing and prescribing cascades, can lead to polypharmacy, particularly in older patients. ${ }^{5}$

The term polypharmacy has been used by the World Health Organization (WHO) to describe the concurrent use of multiple medications. Although there is no standard consensus, polypharmacy is often defined as the routine use of five or more medications. ${ }^{5}$ Some authors have referred to polypharmacy as the use of a greater number of drugs than clinically indicated, because the use of multiple drugs may be appropriate for treating complicated clinical conditions or multiple comorbidities in an individual. ${ }^{6}$ According to the circumstances, including the reasons for and the modes of prescription, polypharmacy can be appropriate (rational prescribing of multiple medicines based on the best available evidence and considering individual patient factors and context), or inappropriate (irrational prescribing of too many medicines, such that the harms potentially outweigh the benefits). $5,7,8$

Inappropriate polypharmacy, especially in older people, imposes a substantial burden of adverse drug events, decreased physical and social functioning, increased risk of falls, delirium and other geriatric syndromes, hospitalization, and even death. ${ }^{7,8}$ The WHO emphasizes that it is necessary to reduce inappropriate polypharmacy and practice appropriate polypharmacy. ${ }^{5} \mathrm{~A}$ Brazilian study compared the prevalence of polypharmacy considering the number of prescribed medications (five or more) with the prevalence of polypharmacy, considering the quantity of prescribed drugs and the prescription of one PIM in older people. The study showed that the adoption of different concepts of inappropriate and appropriate polypharmacy resulted in different prevalences. ${ }^{9}$

If the primary aim of rational therapeutics is to ensure that patients receive the drugs they need and no more ${ }^{6}$ then why does polypharmacy occur so frequently? Several causes can be identified. The most common are multiple providers, each of whom prescribe medications, creating a growing list of drugs on a patient's profile; as the population ages, the incidence of chronic conditions and multimorbidity increases; clinical practice guidelines rarely address the treatment of older patients with three or more chronic diseases and the psychosocial aspects of both the disease and treatment; adverse drug reactions that may be interpreted as new medical conditions; ${ }^{10}$ and an irregular practice of performing a medication review when assessing older patients. ${ }^{11}$

Therefore, the major intervention to reduce PIM and inappropriate polypharmacy is to apply the principles of appropriate prescription: ${ }^{2,5,8,12}$

1. Accurate diagnosis is underpinned not only by an understanding of basic pathophysiology, ${ }^{2}$ but also with a comprehensive geriatric assessment. This is a multidimensional tool that evaluates several domains, including physical function, cognition, nutrition, comorbidities, psychological status, and social support, with the aim of identifying the "functional age" of older people; ${ }^{13}$ 
2. Do no harm, only prescribe a drug if it is necessary, always ensure an appropriate balance between the benefits and harms of a particular treatment, and consider alternative non-pharmacological approaches whenever possible; ${ }^{2,12}$

3. Check all current medications and the reasons for each one; identify essential medications, including those that should not be stopped without specialist advice, medications with essential replacement functions (e.g., thyroxine), and medications to prevent a rapid symptomatic decline if a different treatment was stopped (e.g., medications for Parkinson's disease); ;,7,8,12

4. Identify factors that might lead to adverse drug events, such as the number and types of drugs, and patient characteristics: for example, age $>80$, cognitive impairment, functional decline, multiple comorbidities, substance abuse, multiple prescribers, past or current nonadherence, and the risk of accidental overdosing; $, 5,7$

5. Choose the best drug for specific patients: assess the appropriate dosage regimen taking into account the patient's susceptibilities and the estimated life expectancy in high-risk patients; consider possible interactions with other drugs, herbal formulations and foods; and consider cost-effective alternatives given that medication costs may have an impact on compliance; ${ }^{2,5,12}$

6. Define overall care goals, as well as patient's values and preferences in the context of life expectancy and "functional age": the relative balance of symptom control and quality of life versus cure or prevention, and patient preferences for aggressive versus conservative care. ${ }^{8}$ Identify the need for adding or intensifying medication therapy in order to achieve therapeutic objectives, including symptom control, biochemical/clinical targets, or the prevention of disease progression/ exacerbation; 5

7. Discuss patients' preferences, the proposed treatment, and its potential effects - both beneficial and adverse; ${ }^{2,5,7}$

8. Carefully monitor effects and adverse reactions, and make dosage adjustments. The patient should be aware of and alert to the main signs and symptoms of adverse events. In addition, patients should understand the importance of contacting the provider(s) in the event of warning signs; 2,11

9. Conduct a medication review regularly and discontinue medications that are no longer needed. These can include medications prescribed for temporary indications, those with higher-than-usual maintenance doses, medications with generally limited benefits for the specific indication or for the specific patient, and unnecessary medications based on the changes in treatment goals in the presence of modifications of life expectancy (i.e. terminality) and/or according to "functional age" (e.g. functional decline, cognitive deficit, frailty); $;$,12,13

10. Implement and monitor a drug deprescribing plan: ongoing reappraisal for illness complications or withdrawal syndromes, communication of plans and shared responsibility among all prescribers, and supervision of drug discontinuation. ${ }^{5,8}$

Deprescribing is the process of tapering, stopping, discontinuing, or withdrawing drugs, with the goal of managing polypharmacy and improving outcomes. ${ }^{5,8} \mathrm{It}$ is a progressive prescribing continuum. ${ }^{7}$ Therefore, deprescribing some drugs due to inappropriate polypharmacy or PIMs does not preclude the continuation of appropriate medications.

Finally, we must change the initial question from "Why am I deprescribing a medication that I should not have prescribed?" into "Would it not have been better to have avoided the inappropriate prescription in the first place?" We must remember that most of the time, less is more. This is perfectly applicable to drug prescriptions.

\section{ACKNOWLEDGMENTS}

The authors gratefully acknowledge the MPI Brazil Project team and Coordination for the Improvement of Higher Education Personnel (Coordenação de Aperfeiçoamento de Pessoal de Nivel Superior - CAPES).

\section{CONFLICT OF INTERESTS}

The authors declare that there is no conflict of interests.

\section{FUNDING}

Coordination for the Improvement of Higher Education Personnel (Coordenação de Aperfeiçoamento de Pessoal de Nivel Superior - CAPES).

\section{AUTHORS' CONTRIBUTION}

WWA, LCP and MGO conceived and wrote the manuscript. All authors read and approved the manuscript. 


\section{REFERENCES}

1. Aronson JK. A prescription for better prescribing. Br J Clin Pharmacol. 2006;61(5):487-91. https://doi.org/10.1111/j.1365-2125.2006.02649.x

2. Aronson JK. Rational prescribing, appropriate prescribing. Br J Clin Pharmacol. 2004;57(3):229-30. https://doi.org/10.1111/j.13652125.2004.02090.x

3. Buetow SA, Sibbald B, Cantrill JA, Halliwell S. Appropriateness in health care: Application to prescribing. Soc Sci Med. 1997;45(2):261-71. https://doi.org/10.1016/S0277-9536(96)00342-5

4. Oliveira MG, Amorim WW, Oliveira CRB, Coqueiro HL, Gusmão LC, Passos LC. Brazilian consensus of potentially inappropriate medication for elderly people. Geriatr Gerontol Aging. 2016;10(4):168-81. https:// doi.org/10.5327/Z2447-211520161600054

5. World Health Organization. Medication Safety in Polypharmacy: technical report [Internet]. Geneva: World Health Organization; 2019 [Accessed in May 16, 2020]. Available from: https://apps.who.int/iris/ handle/10665/325454

6. Bennett F, Ferner R, Sofat R. Overprescribing and rational therapeutics: Barriers to change and opportunities to improve. Br J Clin Pharmacol. 2020. https://doi.org/10.1111/bcp.14291

7. Scott IA, Hilmer SN, Reeve E, Potter K, Le Couteur D, Rigby D, et al. Reducing inappropriate polypharmacy: the process of deprescribing.
JAMA Intern Med. 2015;175(5):827-34. https://doi.org/10.1001/ jamainternmed.2015.0324

8. Kouladjian L, Chen TF, Hilmer SN. First do no harm: a real need to deprescribe in older patients. Med J Aust. 2015;202(4):178-9. https:// doi.org/10.5694/mja14.01486

9. Gomes MS, Amorim WW, Morais RS, Gama RS, Graia LT, Queiroga HM, et al. Polypharmacy in older patients at primary care units in Brazil. Int J Clin Pharm. 2019;41(2):516-24. https://doi.org/10.1007/s11096-018-00780-5

10. Austin RP. Polypharmacy as a risk factor in the treatment of type 2 diabetes. Diabetes Spectr. 2006;19(1):13-6. https://doi.org/10.2337/ diaspect.19.1.13

11. Tarn DM, Paterniti DA, Kravitz RL, Fein S, Wenger NS. How do physicians conduct medication reviews? J Gen Intern Med. 2009;24(12):1296-302. https://doi.org/10.1007/s11606-009-1132-4

12. Aronow WS, Frishman WH, Cheng-Lai A. Cardiovascular drug therapy in the elderly. Cardiol Rev. 2007:15(4):195-215. https://doi.org/10.1097/ CRD.0b013e3180301b69

13. Soto-Perez-de-Celis E, Li D, Yuan Y, Lau YM, Hurria A. Functional versus chronological age: geriatric assessments to guide decision making in older patients with cancer. Lancet Oncol. 2018;19(6):e305-16. https:// doi.org/10.1016/S1470-2045(18)30348-6 